\title{
Development of Neural Selectivity for Birdsong during Vocal Learning
}

\author{
Susan F. Volman \\ Division of Biology, Caltech, Pasadena, California 91125 and Department of Zoology, The Ohio State University, \\ Columbus, Ohio 43210
}

\begin{abstract}
Juvenile white-crowned sparrows learn to sing by first memorizing an adult's song and then progressively matching their vocalizations to this model during plastic song. Previous studies have shown that neurons in the song-system nucleus HVC of adult sparrows respond preferentially to a bird's own song. In this study, the auditory selectivity of HVC neurons in subadult birds was examined. In young, nonsinging birds who had been song tutored, these cells responded to song stimuli, and at some recording sites had distinct preferences for one song or another. As a population, however, HVC neurons in these birds showed no preference for familiar song. They were no more likely to prefer normal tutor song to reversed tutor song or to the song of another white-crowned subspecies. By contrast, in birds producing plastic song, HVC neurons were selective for the bird's own songs, even in preference to their tutor song. Therefore, during song learning the response properties of HVC neurons appear to be dynamically modified, perhaps by auditory feedback from the bird's own vocalizations. The emergence of song selectivity during plastic song may be significant both for song learning and for song perception in adult birds.
\end{abstract}

[Key words: songbird, auditory selectivity, song system, telencephalon, white-crowned sparrow, zebra finch]

Higher-order telencephalic sensory areas often have highly selective response properties, suggesting that they are involved in the representation and recognition of complex stimuli. The beststudied examples are undoubtedly visual neurons in the primate temporal cortex, which have been shown to respond selectively to objects and faces, and are, in some cases, sensitive to facial identity or familiarity (reviewed by Gross, 1992; Perrett et al., 1992; Rolls, 1992; also Young and Yamane, 1992). Even in this well-studied part of the brain, there have been relatively few investigations of how an individual's experience influences the neuronal responses (Miyashita, 1988; Rolls et al., 1989; Rodman et al., 1991). Auditory neurons in the avian "song system"

\footnotetext{
Received Dec. 7, 1992; revised May 7, 1993; accepted May 11, 1993.

I thank Dr. D. Margoliash for technical advice and computer programs, Dr. M. Konishi for support and advice, G. Akutagawa and G. Demeurre for help rearing the birds, and S. Mauresberg for the anatomical analyses. Drs. Konishi, Margoliash, A. J. Doupe, and M. Masters and two anonymous reviewers made helpful suggestions on various versions of the manuscript. The Bodega Marine Laboratory of the University of California kindly allowed us to collect birds on their preserve. Support was provided by NIH Grant NS07714.

Correspondence should be addressed to Dr. Susan F. Volman, Department of Loology, The Ohio State University, Columbus, Ohio 43210.

Copyright (C) 1993 Society for Neuroscience $0270-6474 / 93 / 134737-11 \$ 05.00 / 0$
}

(an interconnected set of nuclei involved in song learning and production) provide another example of cells with complex, selective responses, which may be involved in the perception of birdsong. In adult songbirds, forebrain song-system neurons respond chiefly to birdsong, and in general they respond best to a bird's own song (Margoliash, 1983, 1986, 1987; Margoliash and Konishi, 1985; Doupe and Konishi, 1991; Margoliash and Fortune, 1992). Because birdsong is learned, and a bird's lifetime exposure to both its own and others' songs can be controlled, this system offers a unique opportunity for examining the role of experience in the acquisition of neuronal selectivity to complex stimuli.

The song-system nucleus HVC (the higher vocal center, formerly misnamed hyperstriatum ventrale pars caudale) receives input from field $\mathrm{L}$, the avian analog of auditory cortex (Kelley and Nottebohm, 1979; Fortune and Margoliash, 1992). In adult white-crowned sparrows (Zonotrichia leucophrys nuttalli), a subpopulation of HVC neurons responds vigorously only to specific, correctly ordered combinations of phrases from the bird's own song (Margoliash, 1983). For example, some HVC neurons fire only during the second phrase of a specific twophrase combination and are unresponsive to either of the two phrases played alone or in reverse order. Such neurons also respond less well to similar phrase combinations from the songs of other individuals or to temporally and spectrally altered versions of the bird's own song. Although such highly specific units constitute only a subset of HVC neurons, systematic sampling from multiunit clusters has shown that song selectivity is a general property of this nucleus (Margoliash, 1986). One clear manifestation of this selectivity is that, at the vast majority of recording sitcs, the ncural response is greatly reduced, and sometimes inhibited, when song is played backwards. This response selectivity illustrates that HVC neurons are tuned to the dynamic, time-varying frequency and amplitude modulations of song rather than its separate frequency components. In addition to exhibiting a preference for normal, forward song, multiunit clusters in the HVC of white-crowned sparrows almost always respond more vigorously to the bird's own song compared to the songs of other birds, with a descending preference for less similar songs.

Because HVC neurons in adult birds prefer the individual's song, this preference would seem to be acquired during the process of song learning, which involves an interaction between innate factors, the memorization of a song model, and auditory feedback. White-crowned sparrows have a predisposition to learn species-typical vocalizations, but for normal song development young sparrows must hear and memorize the song of an adult during the first few months after hatching (Marler, 1970, 1987; 
Table 1. Treatment groups

\begin{tabular}{|c|c|c|c|c|c|c|}
\hline \multirow[b]{2}{*}{ Bird } & \multirow[b]{2}{*}{ Sex } & \multirow{2}{*}{$\begin{array}{l}\text { Tutor } \\
\text { song }\end{array}$} & \multirow{2}{*}{$\begin{array}{l}\text { Age }^{a} \\
\text { (d) }\end{array}$} & \multirow{2}{*}{$\begin{array}{l}\text { No. of } \\
\text { sites }^{b}\end{array}$} & \multicolumn{2}{|l|}{ Anatomy } \\
\hline & & & & & $\mathrm{HVC}\left(\mathrm{mm}^{3}\right)$ & $\mathrm{SpL}\left(\mathrm{mm}^{3}\right)$ \\
\hline \multicolumn{7}{|c|}{ Nonsinging juvenile birds } \\
\hline Y100 & $\mathbf{M}$ & G46 & 106 & 1 & 0.430 & 0.149 \\
\hline G60 & $\mathbf{M}$ & G46 & 139 & 1 & & \\
\hline B3 & $\mathbf{M}$ & G88 & 152 & 5 & 0.256 & 0.167 \\
\hline B4 & $\mathbf{M}$ & G88 & 157 & 8 & 0.402 & 0.139 \\
\hline W43 & $\mathbf{M}$ & $\mathrm{aG88}$ & 164 & 3 & 0.257 & 0.182 \\
\hline $\mathrm{O} 48$ & $\mathbf{M}$ & W91 & 181 & 1 & & \\
\hline G16 & $\mathbf{M}$ & W91 & 181 & 3 & 0.395 & \\
\hline R54 & $\mathbf{M}$ & G88 & 210 & 1 & & 0.164 \\
\hline $\mathrm{O} 45$ & $\mathrm{~F}$ & W91 & 195 & 5 & & \\
\hline W3 & $\mathrm{F}$ & W91 & 201 & 8 & & \\
\hline W2 & $\mathbf{F}$ & W91 & 209 & 3 & & \\
\hline G20 & $\mathrm{F}$ & W91 & 257 & 8 & & \\
\hline Mean & & & & & $0.348 \pm 0.038$ & $0.160 \pm 0.008$ \\
\hline \multicolumn{7}{|c|}{ Birds singing plastic song } \\
\hline $\mathrm{O} 46$ & $\mathbf{M}$ & W91 & 282 & 2 & & \\
\hline W44 & $\mathbf{M}$ & G88 & 261 & 7 & 0.429 & 0.151 \\
\hline $\mathrm{P} 2$ & $\mathbf{M}$ & G88 & 296 & 3 & & \\
\hline Y96 & $\mathbf{M}$ & G88 & 302 & 5 & 0.583 & 0.208 \\
\hline B2 & $\mathbf{M}$ & G88 & 305 & 5 & 0.448 & 0.163 \\
\hline W47 & $\mathbf{M}$ & G88 & 311 & 6 & 0.592 & 0.183 \\
\hline W45 & $\mathbf{M}$ & G88 & 314 & 6 & 0.342 & 0.179 \\
\hline Y90 & $\mathbf{M}$ & G88 & 321 & 6 & 0.431 & 0.169 \\
\hline W42 & $\mathbf{M}$ & G88 & 334 & 7 & 0.479 & 0.158 \\
\hline S5 & $\mathbf{M}$ & G88 & 340 & 1 & & \\
\hline \multicolumn{3}{|c|}{ Mean $\pm \mathrm{SEM}$} & & & $0.472 \pm 0.034$ & $0.172 \pm 0.006$ \\
\hline
\end{tabular}

a Age at time recordings made in HVC.

${ }^{b}$ Number of recording sites in HVC from which data were used.

Konishi, 1985). White-crowned sparrows can be tutored with tape-recorded song, and if they are kept in isolation after tutoring, their stereotyped, adult song usually does not begin to develop until 8-10 months later. Then, for about 1 month, they sing a variable "plastic song," which is gradually modified until it closely matches the tutor song. If the bird cannot hear itself sing during this time, its song development is abnormal (Konishi, 1965).

When, therefore, during song learning does neuronal selectivity arise? To address this question, I have recorded auditory responses in the HVC of young white-crowned sparrows before and during plastic song. The results indicate that selectivity for a bird's own song arises during plastic song, and therefore may be shaped by auditory feedback from the bird's own vocalizations.

Results from a subset of these birds have been reported in abstract form (Volman and Konishi, 1986, 1987).

\section{Materials and Methods}

Animals. The 22 white-crowned sparrows (Zonotrichia leucophrys nuttalli) used in these experiments were collected as nestlings of approximately $7-12 \mathrm{~d}$ old from coastal sites in California. All birds were then hand reared in isolation from adults. The collecting, rearing, and subsequent physiological experiments were carried out in accordance with a protocol approved by the Caltech Animal Care and Use Committce and also in compliance with recommendations for the use of wild birds in research (American Ornithologists' Union, 1988). Electrophysiological recordings were made from birds in two groups (Table 1): 12 birds (eight males and four females) were 3-8 months old and were not singing, and 10 male birds were 9-11 months old and were in the midst of plastic-song production.

Tutoring and rearing. Tutoring began when birds were about $20 \mathrm{~d}$ old and lasted for 31-33 d. The song was played $2-4 \mathrm{hr} / \mathrm{d}$ at a rate of one song every 7 or $14 \mathrm{sec}$, similar to the rate at which white-crowned sparrows sing during song bouts. The tutor songs were those of adult, wild-caught birds of the nuttalli subspecies. Each bird was tutored with only one song. Three different songs were used in all, and all birds collected at one time were tutored with the same song (see Table 1). During tutoring the birds were housed with their nestmates in group cages, and after tutoring they were housed individually in small acoustic isolation chambers (Industrial Acoustics Corporation or Eckel Industries). The chambers were lighted by broad-spectrum fluorescent bulbs, and the light/dark cycle was adjusted to approximate normal seasonal changes.

Song and song monitoring. The vocalizations of all birds were monitored one or more times a week, starting from when they were about 4 months old, by tape recording via microphones installed in the acoustic chambers. None of the younger birds were singing at the time they were used for physiological experiments, although it is possible that they had previously produced subsong. Subsong is low in volume and the song elements bear little resemblance to adult song (cf. Marler and Peters, 1982, for a description of preadult song in swamp sparrows). The older birds were monitored approximately every $5 \mathrm{~d}$ after they began to vocalize in the spring and every $1-4 \mathrm{~d}$ after plastic song began. Early plastic song was characterized by the presence of recognizable, species-typical song notes. When a bird's plastic song was loud enough to obtain a good recording, the bird was designated to be used for electrophysiology. These plastic songs correspond most closely to Marler and Peters' (1982) stage 3, in which song syllables have minor variations and syllable order is relatively stable. For each bird, two to four (usually three) plastic songs were used as stimuli. These songs were all produced during the 1 or $2 \mathrm{~d}$ before the HVC recording session. Plastic songs produced most often were chosen to be used. Most of these birds sang 
fairly clear imitations of their tutor's song. The songs of two birds, however, were quite different from their tutor's: bird P2, which had been implanted with testosterone, sang an isolate-type song; bird O46 sang a plastic song that was higher in frequency than its tutor's song. Bird P2 was given testosterone in order to accelerate his song production, but because this procedure appeared to compromise song learning, it was not carried out on any other birds (see Korsia and Bottjer, 1991).

In an attempt to silence the younger birds or to produce distorted plastic song in the older birds, I tried a technique that has been used to silence or frequency-shift the songs of adult birds (D. Margoliash and M. Konishi, personal communication). Glass beads (approximately 1$1.5 \mathrm{~mm}$ diameter) were inserted between the two internal tympaniform membranes in 5 of the 12 birds recorded as presinging juveniles, when they were about $75 \mathrm{~d}$, and in 9 of the 10 birds recorded in plastic song, when they were between 90 and $130 \mathrm{~d}$. The syrinx was exposed under Equithesin anesthesia $(2.5-3.0 \mathrm{ml} / \mathrm{kg})$ and the glass bead, held in a pair of forceps, was gently pressed into the space bordered laterally by the tympaniform membranes and caudally by the bronchidesmus. In this position, the bead can stretch the membranes laterally. I had hoped this would ensure that the younger hirds heard no vocalizations, or would cause the plastic songs to be higher in frequency than normal, which would have been useful for testing whether HVC neurons preferred plastic song over tutor song. As it turned out, this procedure was ineffective, except perhaps in bird O46, although his higher-frequency song was just as likely due to his being recorded earlier in plastic song.

Electrophysiology. The methods used for recording from HVC were essentially the same as those used by Margoliash $(1983,1986)$, and I will describe them only briefly here. Birds were anesthetized with Equithesin $(2.5-3.0 \mathrm{ml} / \mathrm{kg}) \mathrm{l}$ or $2 \mathrm{~d}$ before the recording session to attach a stainless steel head post. Recordings were then carried out under urethane anesthesia $(\sim 100 \mathrm{mg} / \mathrm{kg})$ while the bird was anchored by the head post to a stereotaxic holder and suspended in a cloth sling. The bird's temperature was monitored with a cloacal probe and maintained at 39$41^{\circ} \mathrm{C}$. with a heating jacket made from heat tape. The stereotaxic holder was placed in a large, double-walled anechoic chamber (approximately $\left.8 \mathrm{~m}^{3}\right)$ with a speaker located $1.7 \mathrm{~m}$ from the bird. HVC was located stereotaxically through a small hole in the skull, and glass-insulated platinum/iridium microelectrodes were lowered into the brain through the dura with a hydraulic microdrive.

Recording sites were chosen by moving the electrode in $0.2-0.25 \mathrm{~mm}$ steps across the length, width, and depth of HVC. At each site, the vertical position of the electrode was adjusted until there were, typically, two to four large units superimposed on background activity. The size of the larger units was used as an indication of the stability of the activity. Sites were abandoned if the size of these large units changed, if all auditory responses were inhibitory, or if consistent auditory responses could not be obtained.

Songs were presented with the computerized sound analysis/resynthesis system designed and previously described by Margoliash (1983, 1986). This same system also recorded neural activity. Multiunit responses wcrc quantificd by first digitizing (at $5 \mathrm{kHz}$ ) the complete analog waveform from the recording electrode. The digitized signal was then rectified and collected into $10 \mathrm{msec}$ bins. Each song was presented 20 times with a $12 \mathrm{sec}$ intertrial interval. The song was presented first in each trial, and the first $5 \mathrm{sec}$ of activity was collected for analysis. The songs were all less than $2.8 \mathrm{sec}$ long, and in each trial the fifth second was used to obtain an estimate of the average spontaneous activity. Although some songs elicited poststimulus inhibition, this never lasted into the fifth second. The response measure used for comparisons was the summed activity during the song (excitation minus inhibition), normalized for the length of the song. Occasionally, when the response to all elements of a song was very weak, the net response was more inhibitory than excitatory. In these cases the excitatory response only was used for both members of the pair in pairwise comparisons (see below). Such data points arc indicated on the histograms.

The multiunit technique is well suited for measuring the relative efficacy of different songs at a recording site, and it avoids biased selection of any subpopulation of HVC neurons. Furthermore, it allowed me to compare the selectivity of the population of HVC neurons in these younger birds with that measured previously in adults (Margoliash, 1986).

Single units with response properties similar to the "song-specific" or "combination-specific" neurons recorded in adult birds (Margoliash, 1983; Margoliash and Fortune, 1992) were studied when they were encountered. Units were discriminated by a Schmitt trigger, and the time of occurrence of action potentials relative to the stimulus was recorded. For single-unit recordings, the stimuli were repeated 10 times at $7 \mathrm{sec}$ intervals, and spikes were collected into $30 \mathrm{msec}$ bins for the construction of histograms.

Recording sessions lasted for 12-14 hr unless the bird's vital signs warranted an earlier cessation. Birds were killed at the end of the recording sessions.

Stimuli and data analysis. For the multiunit recordings, a set of songs was presented in a different, predetermined, pseudorandom order at each recording site. At some sites, songs presented early in the set were repeated at the end to see if the response had changed, and if this was the case, then other songs were repeated to havc comparable responses for the pairwise comparisons. The stimulus set always included (1) forward and reversed tutor song, (2) one example (the same for all birds) of the song of another subspecies of white-crowned sparrow, and (3) forward and reversed plastic songs for the older birds. Although the stimulus set always included these songs, at some sites the complete set was not presented because of changes in the neuronal population, presumably due to slight movement of the electrode. Many of the younger, nonsinging birds and some of the older birds were also presented with other nuttalli white-crown songs. The other subspecies' song was that of Zonotrichia leucophrys gambelii, which breeds in Alaska but migrates through California. These two subspecies share some syllable types and can learn each other's songs (Baptista and Petrinovich, 1984), but the phrasing of their songs is quite different (see Fig. 3). In this article, the gambelii song will be referred to as "allopatric" song. In addition to the song stimuli, $400 \mathrm{msec}$ noise bursts and tone bursts of various frequencies were presented at some recording sites. In general, the HVC neurons did not respond well to such stimuli, so these responses were not analyzed quantitatively.

Song preferences at each recording site were quantified by first computing the ratios of the responses to each pair of songs of interest (e.g., forward:reverse song). For the older birds, the plastic song that gave the best response at each site was used for comparisons. In order to normalize the response ratios relative to a ratio of 1:1, their logs were used as the unit of analysis for statistical tests, and these are plotted in the figures. Two tests for song preference were made across recording sites for each pair of stimuli: (1) a two-tailed Student's $t$ test was used to determine whether the mean log ratio differed from 0 (equal response to both songs); (2) a sign test was used to detcrminc if more than half of the recording sites preferred one of the two stimuli. The results of these comparisons are summarized in Table 2.

The data for male and female nonsinging birds were compared separately. When given exogenous testosterone, wild-caught adult female white-crowned sparrows will usually produce songs learned from other birds, and some females housed in pairs in the laboratory will sing spontaneously (S. F. Volman, unpublished observations), but tape-tutored females often fail to produce good song copies (cf. Petrinovich and Baptista, 1987), suggesting that they may have failed to memorize the tutor song.

Histology. Electrolytic marker lesions $(2-4 \mu \mathrm{A}$ for $10 \mathrm{sec}$ ) were made in or just below HVC on one to three electrode penetrations in each bird. At the end of each recording session, the bird was perfused or the brain was fixed by immersion in formalin. The brains were cut into 30 $\mu \mathrm{m}$ parasagittal sections and stained with cresyl violet, and in some cases alternate sections were stained with a silver stain for fibers, in order to localize the lesions. The locations of all penetrations were calculated relative to the lesions, and data only from penetrations clearly within the HVC were analyzed.

The volume of HVC was measured in all birds for which there were good histological sections (Table 1). There are missing data points because HVC in some birds became distorted during fixation. Control volumes were measured from nucleus spiriformous lateralis $(\mathrm{SpL})$, a pretectal nucleus. This measurement is missing for bird $\mathrm{G} 16$ because some of the midbrain sections were not mounted. The nuclei were traced from every third section with a camera lucida, and nuclear volumes were then computed with the aid of a digitizing pad interfaced with a computerized measurement system (Sigma Scan, Jandel Corp).

\section{Results}

Qualitative differences between the two groups of birds were apparent in the multiunit HVC auditory responses (Fig. 1). In the younger, nonsinging birds the responses were generally less 
Table 2. Summary of response comparisons

\begin{tabular}{|c|c|c|c|c|c|c|}
\hline & $\begin{array}{l}\text { No. } \\
\text { of } \\
\text { birds }\end{array}$ & $\begin{array}{l}\text { No. } \\
\text { of } \\
\text { sites }\end{array}$ & $\begin{array}{l}\text { Mean } \log \text { (ratio) } \\
\pm \text { SD }\end{array}$ & $t$ test & $\begin{array}{l}\text { Proportion of } \\
\text { ratios }>1(\%)\end{array}$ & Sign test \\
\hline \multicolumn{7}{|c|}{ Nonsinging juveniles } \\
\hline \multicolumn{7}{|c|}{ Forward: reverse tutor song } \\
\hline Male & 8 & 22 & $-0.01 \pm 0.32$ & $p=0.89$ & $9 / 22(41 \%)$ & $p=0.52$ \\
\hline Female & 4 & 24 & $0.01 \pm 0.13$ & $p=0.59$ & $12 / 24(50 \%)$ & $p=1.00$ \\
\hline Total & 12 & 46 & $0.003 \pm 0.24$ & $p=0.93$ & $21 / 46(46 \%)$ & $p=0.66$ \\
\hline \multicolumn{7}{|c|}{ Tutor:allopatric song } \\
\hline Male & 8 & 23 & $-0.10 \pm 0.22$ & $p=0.04^{*}$ & $8 / 23(35 \%)$ & $p=0.21$ \\
\hline Female & 4 & 16 & $-0.08 \pm 0.28$ & $p=0.25$ & $5 / 16(31 \%)$ & $p=0.21$ \\
\hline Total & 12 & 39 & $-0.09 \pm 0.24$ & $p=0.021^{*}$ & $13 / 39(33 \%)$ & $p=0.05$ \\
\hline \multicolumn{7}{|l|}{ Plastic-song birds } \\
\hline \multicolumn{7}{|c|}{ Forward: reverse song } \\
\hline Plastic song & 10 & 39 & $0.35 \pm 0.30$ & $p<0.0001^{* *}$ & $36 / 39(92 \%)$ & $p<0.0001^{* *}$ \\
\hline Tutor song & 10 & 41 & $0.34 \pm 0.24$ & $p<0.0001^{* *}$ & $38 / 41(93 \%)$ & $p<0.0001^{* *}$ \\
\hline \multicolumn{7}{|c|}{ Sympatric: allopatric song } \\
\hline Plastic song & 9 & 38 & $0.29 \pm 0.20$ & $p<0.0001^{* *}$ & $37 / 38(97 \%)$ & $p<0.0001^{* * *}$ \\
\hline Tutor song & 10 & 37 & $0.18 \pm 0.27$ & $p=0.0003^{* *}$ & $25 / 37(67 \%)$ & $p=0.047^{*}$ \\
\hline \multicolumn{7}{|c|}{ Plastic song: tutor song } \\
\hline & 10 & 48 & $0.10 \pm 0.21$ & $p=0.002^{* *}$ & $30 / 48(63 \%)$ & $p=0.18$ \\
\hline
\end{tabular}

${ }^{a}$ Number of birds from which data in each category were used.

$* 0.02<p<0.05$.

$* * p<0.02$.

robust and tended to habituate more easily than those in the older, singing birds. At some HVC sites in the younger birds, auditory responses, although present, were not sufficiently above background activity to quantify their selectivity. Nevertheless, in general the neurons in these younger birds were more likely to respond to song than to tone or noise bursts. At most recording sites in the older birds, on the other hand, the response to one or more of the song stimuli was well above background.

Physiological differences between the two groups of birds were not accompanied by a major difference in HVC volume. Postnatal increases in the size of HVC have been observed in several songbird species (Bottjer et al., 1985; Alvarez-Buylla et al., 1988; Nordeen and Nordeen, 1988), but significant changes seem to occur only during song memorization and not during the plasticsong stage (Nordeen et al., 1989; Alvarez-Buylla et al., 1992). Consistent with these studies, HVC was smaller in the younger, nonsinging males (Table $1 ; N=7,5 ; T=2.45 ; p=0.037$ ), but when its volume was corrected for that of the control nucleus, there was no significant difference between the two groups ( $N$ $=7,4 ; T=1.30 ; p=0.28$ ).

\section{Auditory responses in juvenile, nonsinging birds}

HVC neurons in the nonsinging birds preferred their normal tutor song to its reverse at only $46 \%$ of the recording sites (Table 2, Fig. 2). In both males and females, the number of sites where forward song was the better stimulus was no larger than expected by chance. There were enough data recorded from birds tutored with two of the tutor songs to consider these songs separately. Forward tutor song W91 produced more excitation than its reverse at 15 of 28 recording sites (sign test, $p=0.85$ ), and forward tutor song G88 was the better stimulus at 5 of 16 sites ( $p=0.21$ ). By all measures, then, there was no evidence of selectivity for familiar song in these comparisons of forward and reverse song. This lack of preference for forward songs contrasts markedly to the results of similar experiments in adult birds (Margoliash, 1986), where $96 \%$ of recording sites responded better to the forward version of the birds' own songs, and $77 \%$ of the sites preferred this version of other conspecific whitecrown songs.

Forward and reverse song did not always elicit similar responses. At many recording sites one song direction was substantially better. For example, at $24 \%$ of the sites one stimulus produced at least 1.5 times $(\log =0.18)$ the response of its opposite, and at $15 \%$ of the sites, the response to one song direction was at least two times $(\log =0.3)$ more excitatory. At these sites, therefore, response strength depended on the dynamic, frequency-with-time characteristics of the stimuli.

As a second measure of selectivity in the nonsinging birds, tutor song was compared to the allopatric gambelii subspecies song (Fig. 3). There was no preference for either song when the two sexes were considered separately. There was, however, a tendency for the unfamiliar song to elicit a stronger response, and in the combined data for males and females this preference was significant by the $t$ test measure, and almost significant in the sign test (see Table 2). In birds tutored with song W91, tutor song was more effective than allopatric song at 8 of 20 sites ( $p$ $=0.50$ ), whereas in birds tutored with song G88, tutor song was the better stimulus at only 3 of 17 sites $(p=0.01)$. Thus, the preference for unfamiliar song in the collective data is mostly attributable to birds tutored and tested with song G88. Highly differential responses to the two subspecies' songs occurred at more recording sites than with forward and reverse songs. For example, at $31 \%$ of the sites, one subspecies' song was at least twice as excitatory as the other.

No systematic attempt was made to record from the subpopulation of HVC neurons, previously described for adult birds, 
A
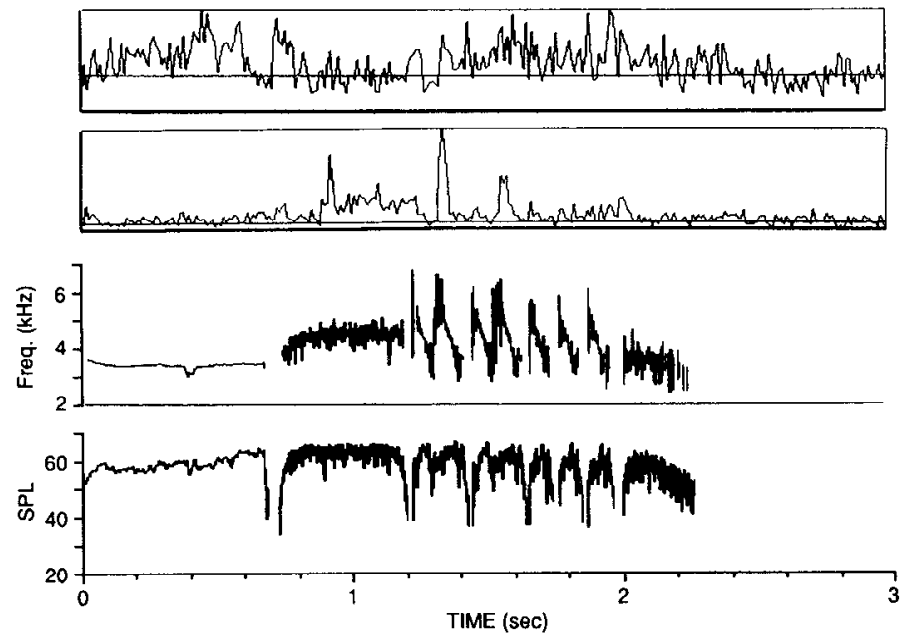

TIME (sec)
B1
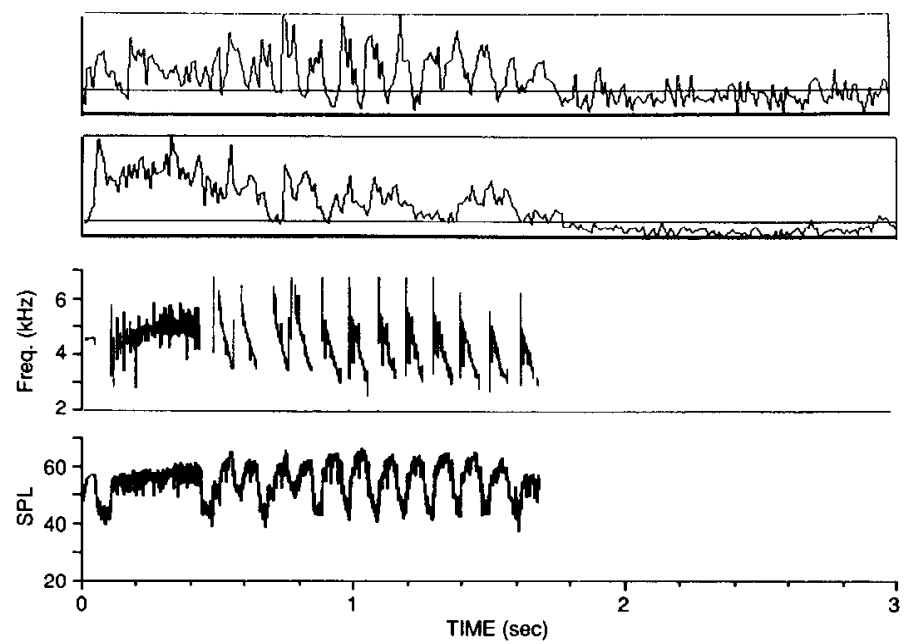

B2
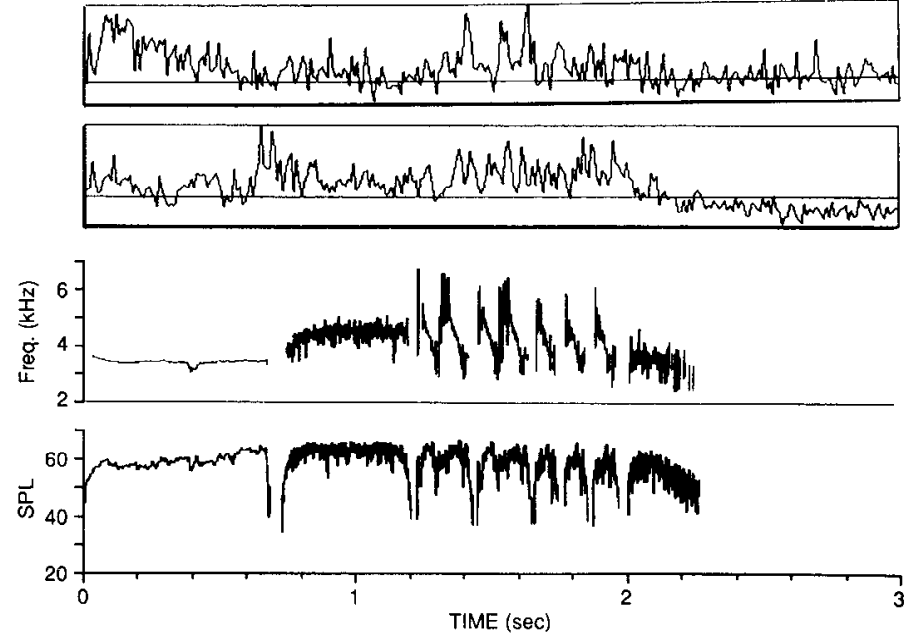

Figure 1. Examples of multiunit responses in a male, nonsinging bird $(A)$ and a bird singing plastic song $(B)$. Each record is the mean response to 20 song presentations. The responscs arc plottcd on an arbitrary scalc and normalized to full scale, and the thin lines represent the average spontaneous activity at each site. Therefore, the relative response strengths across records can be visually estimated by noting the differences in the height of the peak responses above background activity. The bottom two traces in each panel show the song frequency and amplitude spectra. $A$, Nonsinging bird: response to tutor song at two sites. At the first site there was a weak response throughout most of the song. By contrast, neurons at the second site responded briskly to only a few notes. Weak responses such as at the first site were more common in the younger birds. $B 1$, Plastic-song bird: response to bird's own song at two recording sites. At the first site, there was a moderate response mainly during each note in the trill portion of the song. At the second site, several song phrases elicited strong excitation. $B 2$, Response to tutor song at the same sites shown in $B 1$. At both sites, the neurons responded to similar elements in the tutor and plastic songs, but the response to the plastic song exceeded that to the tutor song by ratios of $1.33: 1$ and $1.73: 1$, respectively.

that require more than one song phrase for optimal response (Margoliash, 1983). However, some well-isolated units with such properties were recorded in both male and female nonsinging birds. For example, the unit shown in Figure 4 responded strongly during the second phrase of the tutor song, and its response was diminished if the second phrase was not preceded by the first phrase (Fig. 4, top) or by a tone burst that simulated the first phrase (not shown). Units that responded best or exclusively to correctly ordered phrase combinations did not necessarily prefer tutor song. This cell, for example, responded differentially to three other white-crown songs, but its response to one of them was as strong as that to the tutor song (Fig. 4, bottom). Such units illustrate the sensitivity of HVC neurons in the younger birds to dynamic song properties, even while the population was not selective for a particular song, or for forward over reverse song.

\section{Auditory responses in plastic-song birds}

In the multiunit responses from the birds singing plastic song there were strong preferences for forward song and for the birds' own subspecies' song (Fig. 5, Table 2). These preferences were clear when either tutor song or the birds' own plastic songs were played. Forward plastic song was preferred at 36 of 39 recording sites, and forward tutor song was preferred to reversed tutor song at 38 of 41 recording sites. Compared to the presinging birds, not only did forward song consistently produce a better responsc than its reversc, but also there were many more sites with a large response difference. In the combined data for plastic 


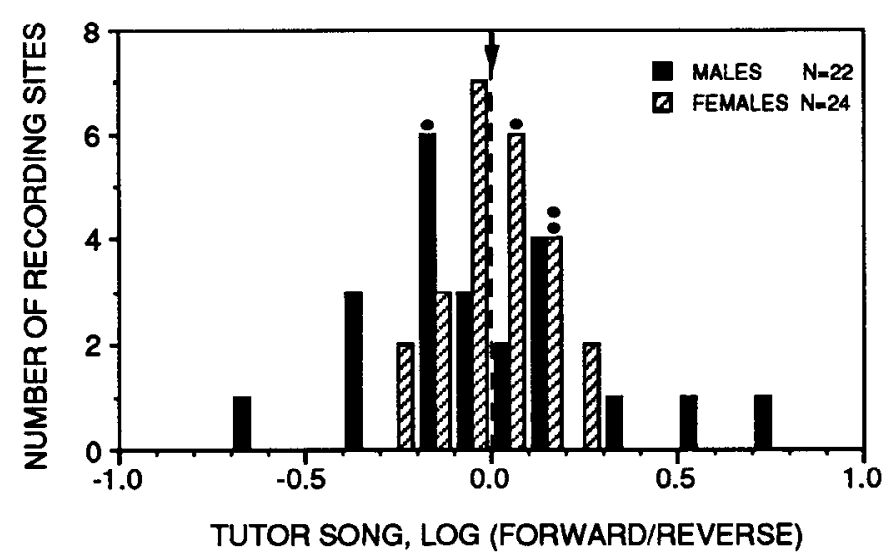

Figure 2. Distribution of response ratios for tutor song compared to reverse tutor song in the HVC of juvenile nonsinging birds. The dashed line indicates an equal response to the two songs. The data from males and females are plotted with different symbols. The log of the response ratios is distributed evenly around 0 , with a mean for the males and females combined of -0.003 (arrow), corresponding to a mean response ratio of $0.99: 1$, tutor:reversed song (see Table 2 for statistical analyses). At four recording sites (three in female birds and one in a male bird) there was a net inhibitory response to one of the two stimuli, and therefore the ratios were computed from the excitation only (see Materials and Methods). The histogram bars that contain these data points are indicated with dots.

and tutor song, the response to forward song (or reversed song at two sites) was at least 1.5 times greater at $71 \%$ of the recording sites, and at least two times greater at $56 \%$ of sites, compared to only $15 \%$ in the younger birds.

At most sites there was also a preference for plastic or tutor song over allopatric song (Fig. $5 B$, Table 2). The proportion of sites where plastic song was more excitatory than the allopatric, gambelii song was 37 of 38 , while nuttalli tutor song was preferred to gambelii song at 25 of 37 sites. These preferences differed from those in the younger birds only in respect to which song was preferred, and not significantly in the magnitude of the ratios: $36 \%$ of the sites had ratios of at least $2: 1$ or $1: 2$, compared to $31 \%$ in the younger birds.
Many, but not all, of the plastic songs were quite similar to tutor song (Fig. 6), and the neural responses to both song types were also often similar. Nevertheless, there was a significant, though small, preference for the birds' own plastic songs (Fig. 7). This preference was highly significant for the mean log of the response ratios $(0.10 ; p=0.002)$, but the proportion of recording sites that preferred plastic song was not significantly different from chance ( 28 of $48 ; p=0.18$ ). The two birds whose songs were most different from their tutor's (see Materials and Methods) showed some of the strongest preferences for their own songs (Fig. 7, hatched bars), although a significant preference for plastic song remained when the data from these two birds were excluded ( $t$ test, $p=0.025$ ). Thus, songs produced just prior to the HVC recordings were slightly preferred to the tutor song, and in general the more plastic song differed from tutor song, the more strongly it was preferred.

Different plastic songs were preferred at different recording sites within an individual bird. In eight birds, I tested two or three plastic songs at three or more recording sites. In every one of these birds, each song was preferred over the others in at least one site. These preferences, however, were small in magnitude (Fig. 8). The response to the better plastic song exceeded that to the second best by a ratio of $1.5: 1(\log 0.18)$ or more only $18 \%$ of the time.

Some single units in the plastic-song birds also responded primarily or exclusively to combinations of song phrases (Fig. 9). Of seven such units studied in detail (Fig. 10), five preferred at least one plastic song to tutor song, one responded equally to tutor song and a plastic song, and one preferred tutor song to all three plastic songs tested. Two of these cells were also tested with conspecific songs similar to the tutor's. In both cases, these songs were inferior stimuli.

\section{Discussion}

The results show that auditory responses are present in the HVC of juvenile, nonsinging birds, but as a population these neurons are not selective for familiar song. The emergence of selectivity in the older birds suggests that it may be produced by auditory feedback during the second stage of song learning in which birds
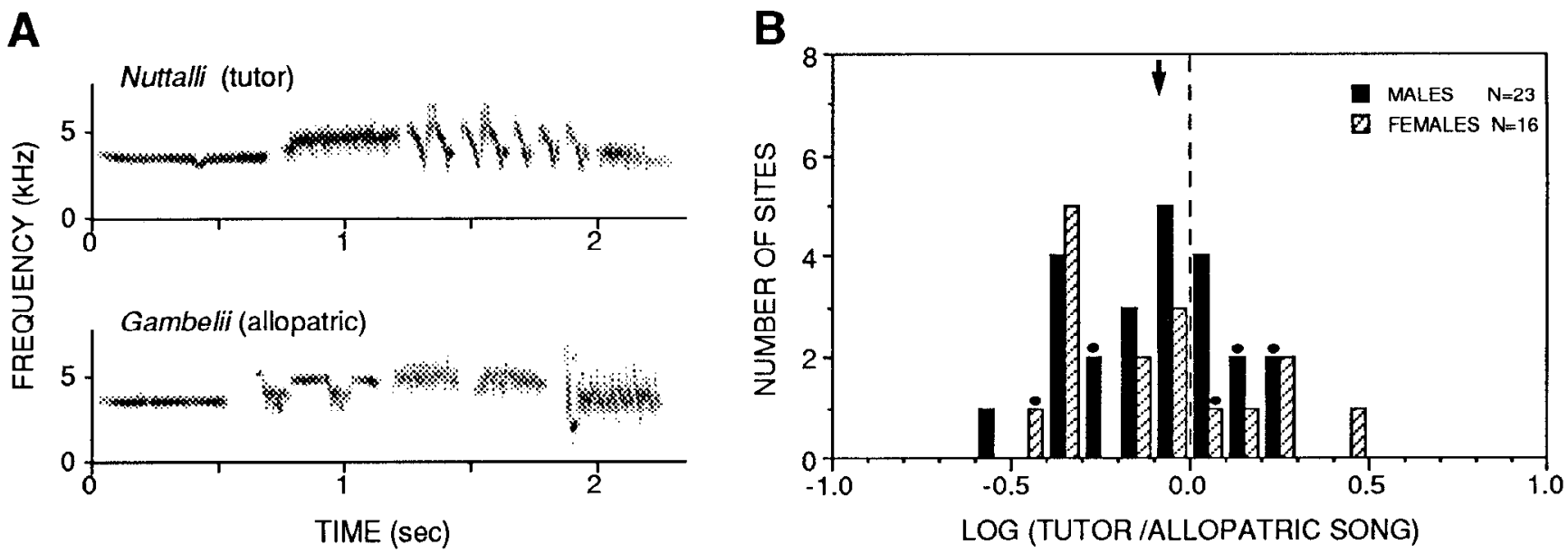

Figure 3. Comparison of response to two subspecies' songs in nonsinging birds. A, Sonogram of a nuttalli tutor song and the gambelii song used in all tests of allopatric song. $B$, Distribution of response ratios for tutor song versus allopatric song. In both males and females, there was a small preference for the unfamiliar song over tutor song (see Table 2 for statistical analyses). The combined mean log(ratio) for males and females was $-0.09 \pm 0.24(p=0.021)$, corresponding to a mean response ratio for tutor:allopatric song of $0.81: 1$. See Figure 2 for the significance of the dots above some of the bars. 

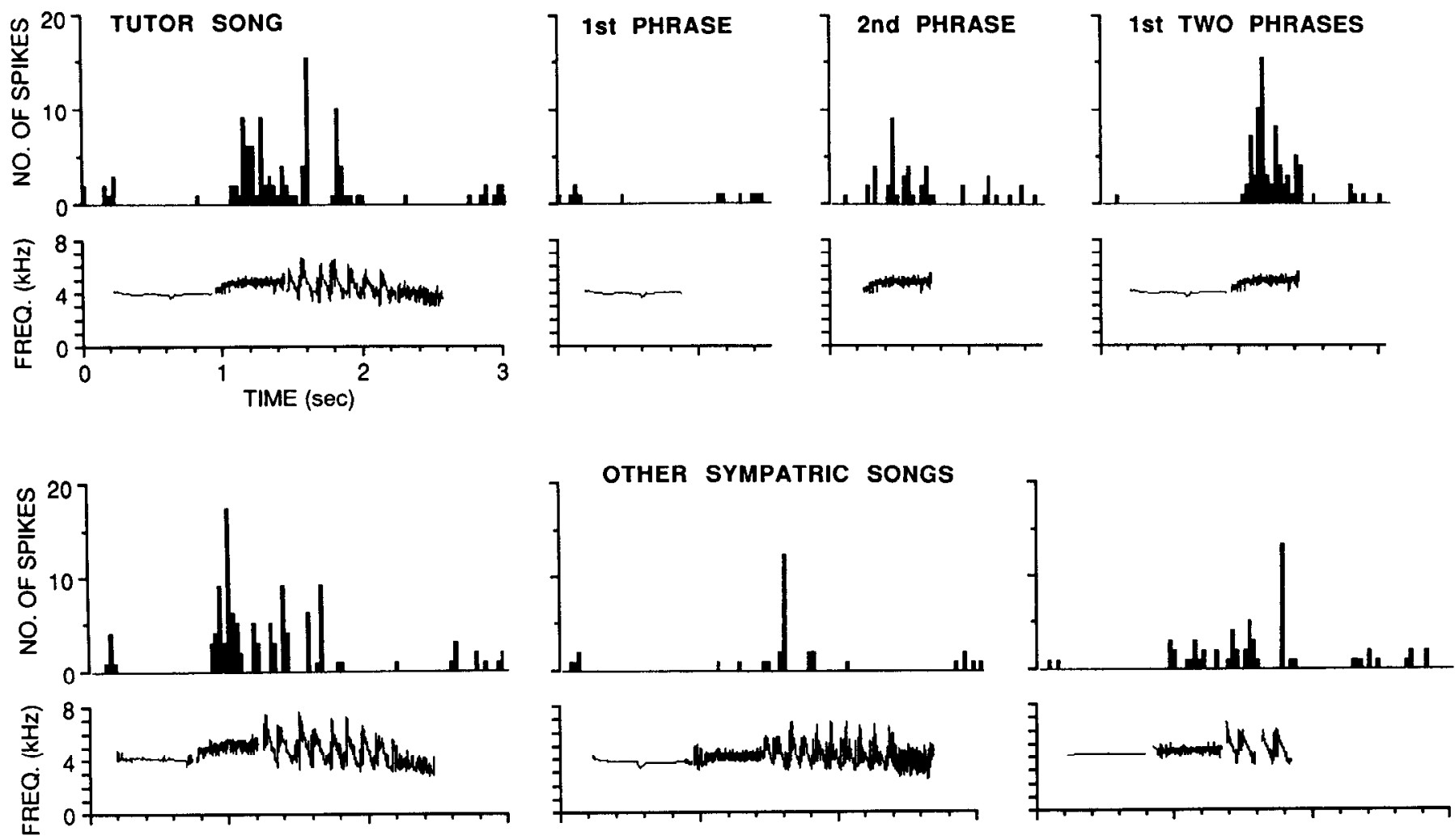

Figure 4. Single "combination-specific" neuron in a nonsinging male bird. Each histogram is the sum of 10 presentations of the stimulus. The top panel shows that response during the second song phrase was reduced when the first phrase was not present. The bottom panel shows the response to three other similar conspecific songs. The response to the first of these was no different from that to tutor song, whereas the other two songs produced weaker responses.

listen to their own vocalizations and match them to a memorized song model.

It is unlikely that a preference for tutor song in the younger birds was somehow masked by their less robust auditory responses. At some recording sites in these birds, responses were well above background (e.g., second record in Fig. $1 A$ ), yet such sites were just as likely to prefer reversed or allopatric song as were sites with weaker responses. It remains possible, however, that highly selective responses are present elsewhere in the brain of juvenile birds after tutoring, and these are then conveyed to HVC by the development of afferent input during plastic song. In this case, the preference of HVC neurons for plastic song over tutor song might reflect inaccurate memorization of the song model rather than shaping of the neural responses by au-
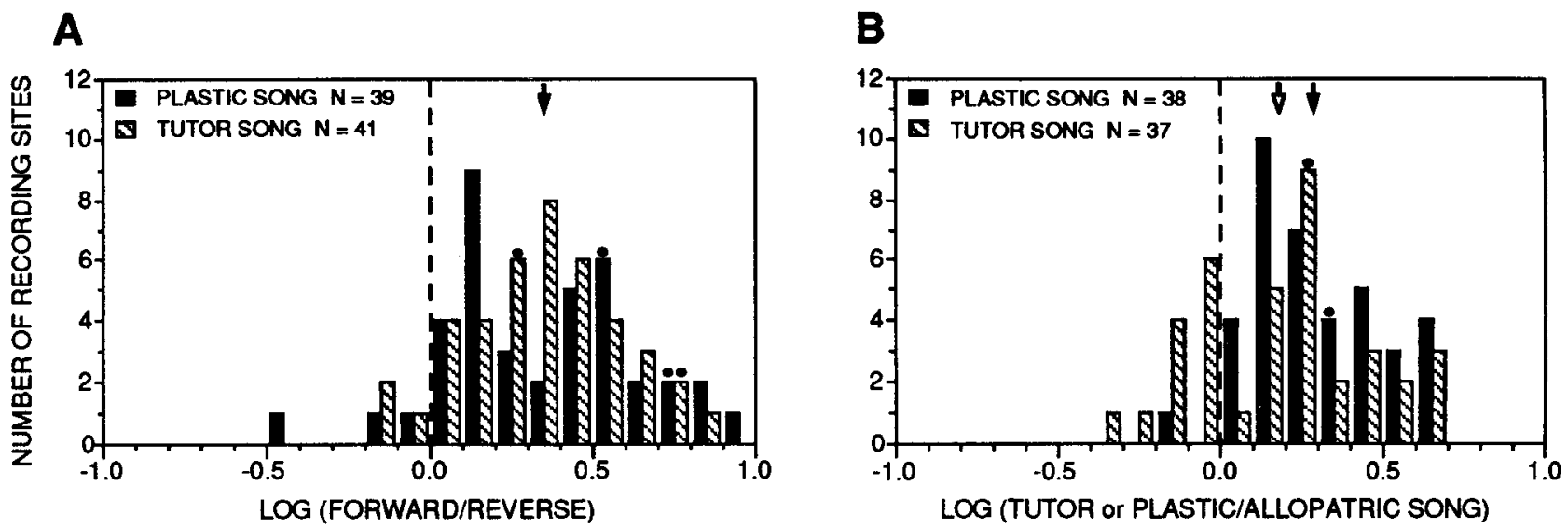

Figure 5. Distribution of response ratios in birds singing plastic song. Comparisons for tutor song and for the birds' own plastic songs are shown with different symbols. $A$, Forward versus reverse plastic and tutor song. With plastic song, the mean $\log ($ ratio) was $0.35 \pm 0.30$ (arrow), corresponding to a mean forward:reverse ratio of $2.23: 1$. Reversing the tutor song also reduced the response: $\operatorname{mean} \log ($ ratio $)=0.34 \pm 0.24$; mean absolute ratio $=2.18: 1$. $B$, Response to allopatric song versus plastic and tutor song. The mean $\log$ (ratio) was $0.29 \pm 0.20$ (solid arrow) for plastic song, and 0.18 \pm 0.27 (open arrow) for tutor song. These correspond to mean response ratios of 1.95:1, allopatric:plastic song, and 1.51:1, allopatric:tutor song. Dots indicate data points with net inhibitory responses, as in Figure 2. 


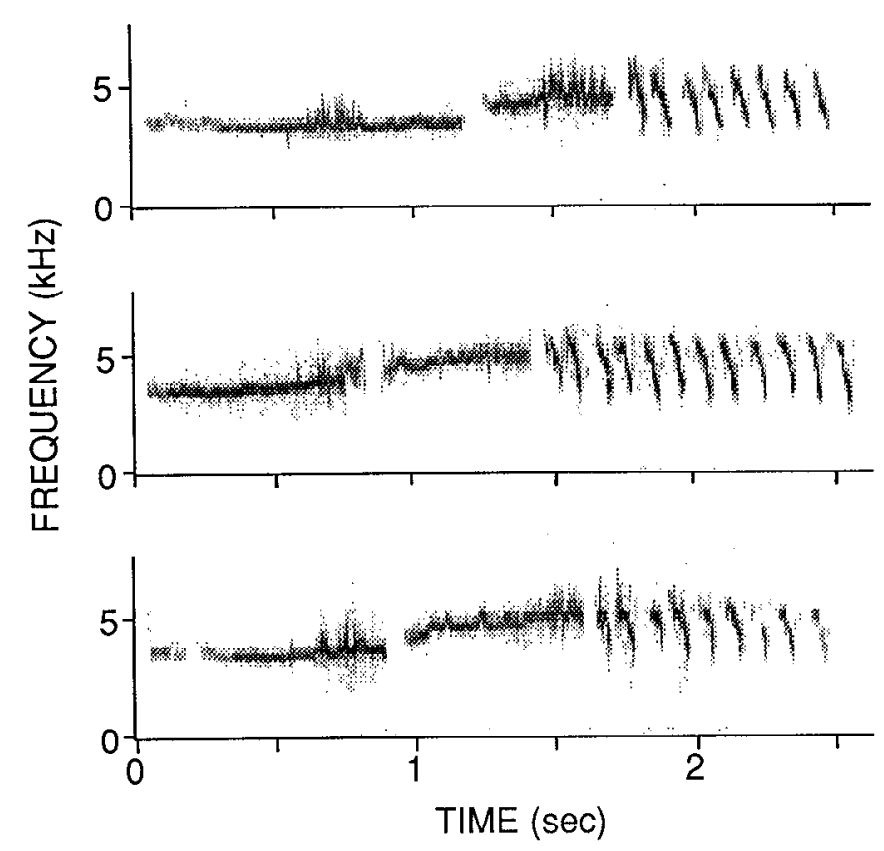

Figure 6. Three plastic songs of bird W45. This bird was tutored with the song shown in Figure 3. These plastic songs differ from cach other most clearly in the duration and stability of the initial whistle, and in the "buzziness" of the second phrase. They all have longer final trills and are missing the terminal buzz from the tutor song. Figure 9 shows two plastic songs of another bird, S5, which differed more substantially from the same tutor song.

ditory feedback. It seems more likely, however, that the preferences of HVC neurons are, at least in part, continuously modified by the birds' own vocalizations for the following reason. Some of these birds would have improved their match to the tutor song as plastic song continued. Thus, a mismemorized tutor song would not necessarily resemble a bird's plastic songs more than its original tutor song. A clear distinction between these two hypotheses awaits future experimental manipulation of auditory experience during the plastic-song stage.

Selectivity for a bird's own song might arise because some connections from lower-level auditory areas are strengthened by consistent stimulation during plastic song, while other connections are eliminated. If this is the case, development of song selectivity could share mechanisms with other systems, such as vertebrate visual systems, where activity-dependent processes lead to the selective retention and strengthening of connections (reviewed by Constantine-Paton et al., 1990; Shatz, 1990). Although little is currently known about the nature or pattern of convergence of auditory inputs in HVC (Fortune and Margoliash, 1992), one of the substrates believed to underlie activitydependent effects - the NMDA class of glutamate receptors is present in the HVC of zebra finches before the plastic-song stage of song learning (Aamodt et al., 1992). It is not yet known, however, if these receptors mediate auditory responses within $\mathrm{HVC}$, nor are there any known neurochemical or anatomical changes that could suggest why auditory responses in HVC are malleable in response to self-produced plastic song, but apparently not to tutoring.

\section{Possible functions of song system auditory responses}

The development of selective auditory responses in HVC may help guide the formation of correct connections from $\mathrm{HVC}$ to

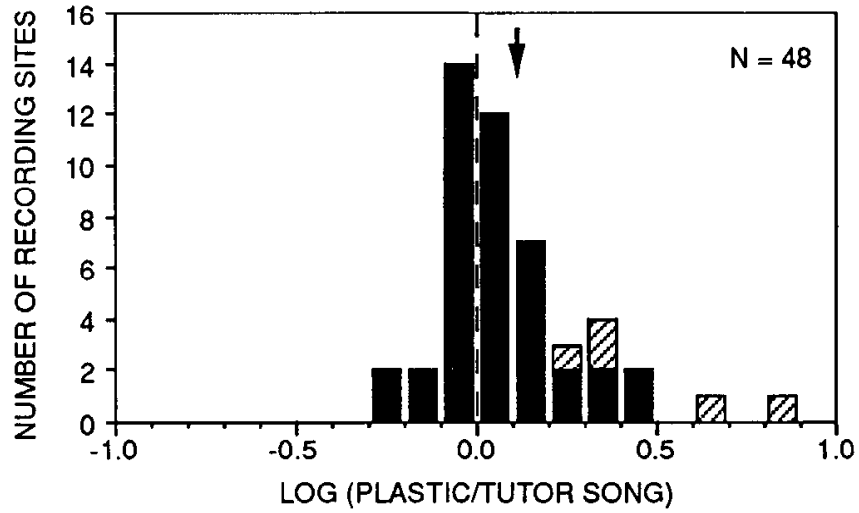

Figure 7. Preference for plastic song over tutor song. Crosshatched bars, sites from two birds whose songs differed most from the tutor song. Arrow, mean $\log ($ ratio), which corresponds to a mean response ratio for plastic:tutor song of 1.26:1. See Results and Table 2 for statistical analyses.

the song-system nucleus RA (robustus archistriatalis), which directly innervates syringeal motor neurons. RA receives inputs from both HVC and nucleus IMAN (lateral magnocellular nucleus of the neostriatum) (Nottebohm et al., 1982). IMAN itself is indirectly innervated by HVC (Okuhata and Saito, 1987; Bottjer et al., 1989), is song selective in adult zebra finches (Doupe and Konishi, 1991), and is also nonselective in juveniles (Doupe and Konishi, 1992). Early lesions of IMAN disrupt song development in zebra finches (Bottjer et al., 1984), apparently by arresting song plasticity (Scharff and Nottebohm, 1991). Recent pharmacological studies of RA have shown that both inputs are mediated by glutamate, but the response to IMAN stimulation is more dependent on the activation of NMDA receptors (Kubota and Saito, 1991; Mooney and Konishi, 1991; Mooney, 1992). Mooney (1992) and Aamodt et al. (1992) have suggested that concurrent activation of the HVC and IMAN inputs to RA might selectively reinforce specific connections from $\mathrm{HVC}$ to RA. Thus, during plastic song, as HVC and presumably also IMAN are developing robust, selective auditory responses, their firing patterns should increasingly coincide within their common target.

In addition to a possible role in song development, song selectivity in adult song-system nuclei may be important for song

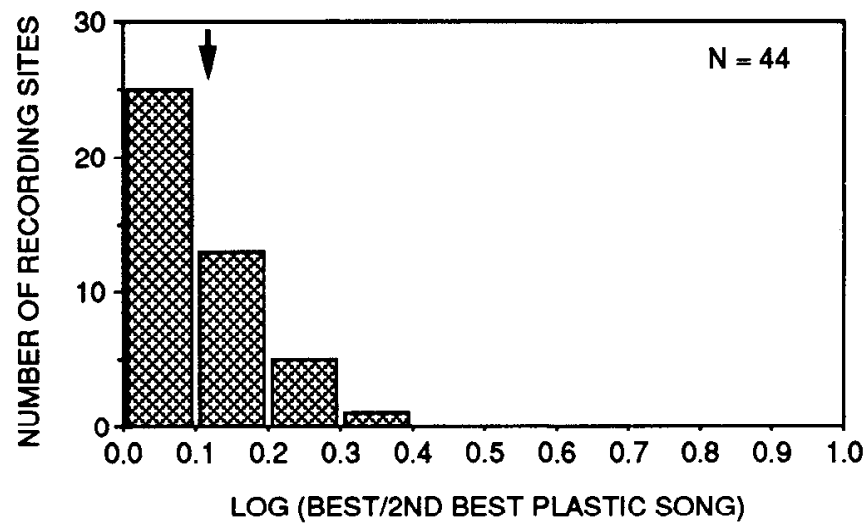

Figure 8. Comparison of responses to best plastic song versus second best plastic song at recording sites where two or more plastic songs were tested. The ratios are all, by definition, greater than $1: 1$. The mean ratio was $1.28(\log =0.11$, arrow). 
PLASTIC SONG 1
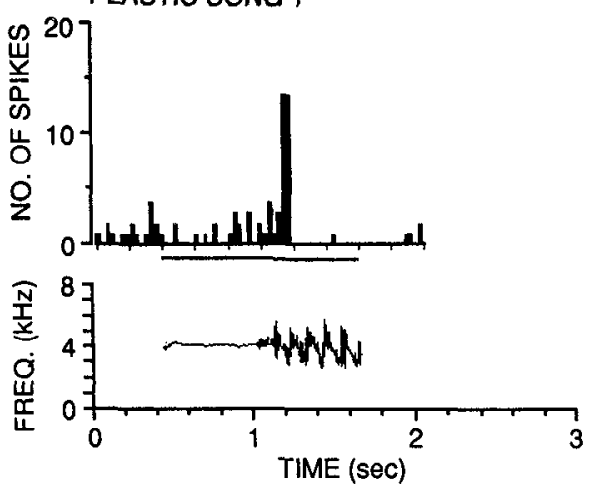

TUTOR SONG

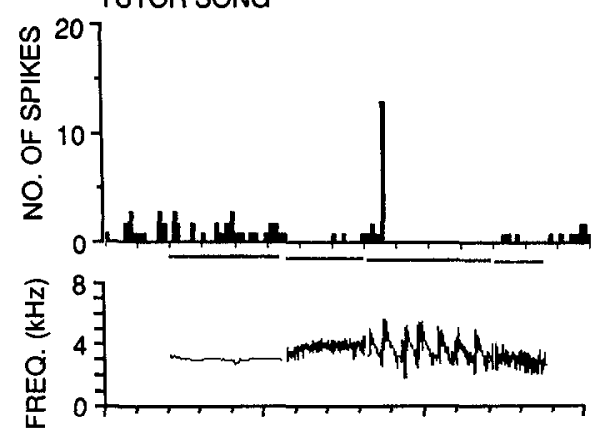

PLASTIC SONG 2
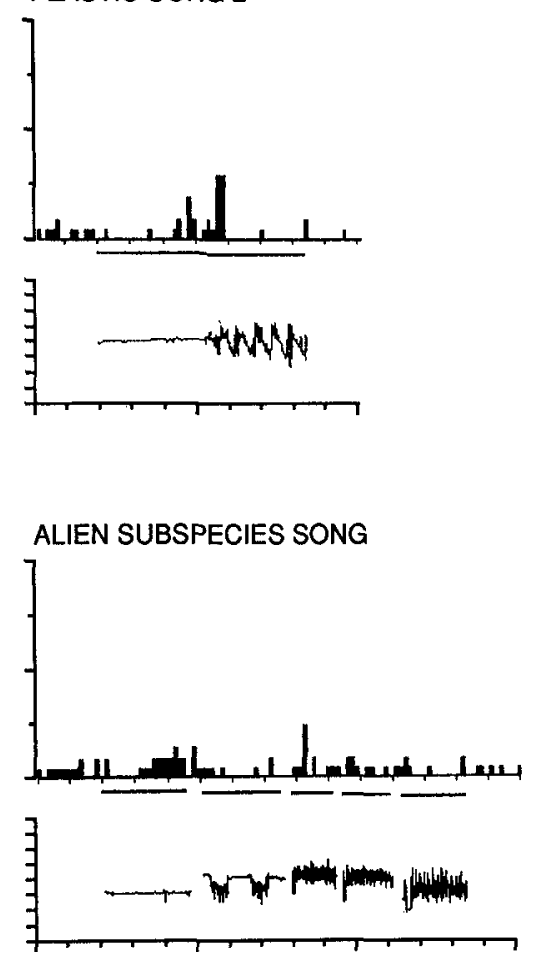

Figure 9. Single unit from a plasticsong bird showing differential response to two plastic songs, tutor song, and allopatric song. Each histogram is the summed response to 10 presentations. As with the unit shown in Figure 4, this cell required a combination of two normally ordered song phrases to respond strongly during the trill (not shown). However, it responded to this phrase whether it occurred second, as in the plastic song, or third, as in the tutor song. Response to the first plastic song was substantially greater than to the second plastic song or to tutor song, and there was little or no response to gambelii song. perception (Margoliash, 1983, 1986, 1987; Williams and Nottebohm, 1985). That is, HVC or other song-system auditory neurons might provide a reference by which the songs of other birds can be recognized by their similarities and differences from a bird's own song. Adult singing birds of a variety of species respond differentially to the songs of individual conspecifics in field studies (e.g., Falls, 1982; Falls et al., 1982, 1988; Yasukawa et al., 1982; McArthur, 1986). Some of these studies, and also laboratory tests of song discrimination (Cynx and Notlebohm, 1992; Weary and Krebs, 1992), have shown that familiarity

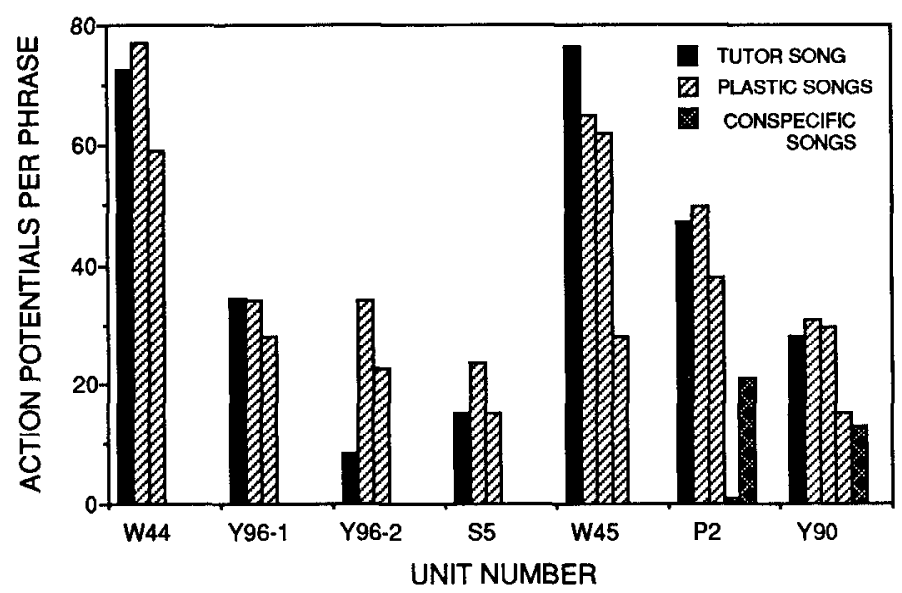

Figure 10. Response of combination-specific units to tutor song, plastic song, and other conspecific songs. The response measure is the total number of action potentials elicited during the best song phrase over 10 presentations of the complete song. If a song was tested more than once, these tests were averaged. Five units responded better to at least one plastic song than to tutor song. The two units tested with other nuttalli white-crowned songs strongly preferred the tutor and/or plastic songs. and/or similarity to a bird's song facilitates song discrimination. Songbirds may also use finc differences in song acoustic parameters to judge the distance of other singing males, particularly if their song is shared (Richards, 1981; Morton, 1982; McGregor and Krebs, 1984). There is some evidence that the song system is involved in song recognition. Lesions of the song-system nucleus area $\mathrm{X}$ in zebra finches impair a bird's ability to discriminate its own song from that of another zebra finch, but such lesions do not affect discriminations between two canary songs (Cynx et al., 1991). Area X, which is innervated by HVC, also responds preferentially to a bird's own song in adult zebra finches (Doupe and Konishi, 1991).

The HVC neurons in the young white-crowned sparrows, while showing no preference for familiar song, did respond differentially at many recording sites to the dynamic features of song, and single-unit responses also showed sensitivity to song features. Such auditory responses may be sufficient for the interspecies discriminations made by young male and nonsinging female birds. Sparrows of various species preferentially learn their own species' songs (Marler, 1970; Marler and Peters, 1977, 1988), and during the sensitive period for song memorization, young swamp sparrows exhibit a stronger cardiac response to conspecific song, compared to song sparrow song (Dooling and Searcy, 1980). Adult female songbirds also recognize their own species' songs, and in some species females use different acoustical features from those used by adult males (Searcy et al., 1981; Searcy and Brenowitz, 1988). Female zebra finches learn to distinguish individual songs, but they take longer than males to do so and show no advantage with familiar songs (Cynx and Nottebohm, 1992). A recent study has examined the role of the song system in interspecies song discrimination: lesions of HVC in female canaries impair their ability to distinguish canary song from white-crowned sparrow song (Brenowitz, 1991). 
The sclcctivity of auditory responses in HVC appears to be shaped, at least in part, by a bird's own vocalizations during plastic song. This finding does not preclude other auditory influences on the responses of song-system neurons. For example, during the plastic-song period, HVC selectivity might also be altered by the songs of other birds. Also, although I found no detectable trace of tutoring in the form of selectivity to tutor song, more subtle changes in HVC or other song-system auditory responses may be determined by this early song exposure. Since tutor song ultimately guides song development, it must at least indirectly modify auditory responses in the song system.

\section{References}

Aamodt SM, Kozlowski MR, Nordeen EJ, Nordeen KW (1992) Distribution and developmental change in $[3 \mathrm{H}] \mathrm{MK}-801$ binding within zebra finch song nuclei. J Neurobiol 23:997-1005.

Alvarez-Buylla A, Theelen M, Nottebohm F (1988) Birth of projection neurons in the higher vocal center of the canary forebrain before, during, and after song learning. Proc Natl Acad Sci USA 85:87228726.

Alvarez-Buylla A, Ling C-Y, Nottebohm F (1992) High vocal center growth and its relation to neurogenesis, neuronal replacement and song acquisition in juvenile canaries. J Neurobiol 23:396-406.

American Ornithologists' Union (1988) Report of committee on use of wild birds in research. Auk 105[Suppl 1]:1 $1-41 \mathrm{~A}$.

Baptista LF, Petrinovich L (1984) Social interaction, sensitive phases and the song template hypothesis in the white-crowned sparrow. Anim Behav 32:172-181.

Bottjer SW, Miesner EA, Arnold AP (1984) Forebrain lesions disrupt development but not maintenance of song in passerine birds. Science 224:901-903.

Bottjer SW, Glaessner SL, Arnold AP (1985) Ontogeny of brain nuclei controlling song learning and behavior in zebra finches. J Neurosci $5: 1556-1562$.

Bottjer SW, Halsema KA, Brown SA, Miesner EA (1989) Axonal connections of a forebrain nucleus involved with vocal learning in zebra finches. J Comp Neurol 279:312-326.

Brenowitz EA (1991) Altered perception of species-specific song by female birds after lesions of a forebrain nucleus. Science 343:303305 .

Constantine-Paton M, Cline HT, Debski E (1990) Patterned activity, synaptic convergence, and the NMDA receptor in developing visual pathways. Annu Rev Neurosci 13:129-154.

Cynx J, Nottebohm F (1992) Role of gender, season, and familiarity in discrimination of conspecific song by zebra finches (Taeniopygia guttata). Proc Natl Acad Sci USA 89:1368-1371.

Cynx J, Scharff C, Nottebohm F (1991) Effects of area X lesions on song discriminations in zebra finches. Soc Neurosci Abstr 17:1051.

Dooling RJ, Searcy MH (1980) Early perceptual selectivity in the swamp sparrow. Dev Psychobiol 13:499-506.

Doupe AJ, Konishi M (1991) Song-selective auditory circuits in the vocal control system of the zebra finch. Proc Natl Acad Sci USA 88: $11339-11343$.

Doupe AJ, Konishi M (1992) Song-selective auditory neurons emerge during vocal learning in the zebra finch. Soc Neurosci Abstr 18:527.

Falls JB (1982) Individual recognition by sounds in birds. In: Acoustic communication in birds, Vol II (Kroodsma DE, Miller EH, eds), pp 237-278. New York: Academic.

Falls JB, Krebs JR, McGregor PK (1982) Song matching in the great tit (Parus major): the effect of similarity and familiarity. Anim Behav 30:997-1009.

Falls JB, Horn AG, Dickinson TE (1988) How western meadowlarks classify their songs: evidence from song matching. Anim Behav 36: $579-585$.

Fortune ES, Margoliash D (1992) Multiple auditory pathways into HVC. Soc Neurosci Abstr 18:1193.

Gross CG (1992) Representation of visual stimuli in inferior temporal cortex. Philos Trans R Soc Lond [Biol] 335:3-10.

Kelley DB, Nottebohm F (1979) Projections of a telencephalic auditory nucleus - field L-in the canary. J Comp Neurol 183:455-470.

Konishi M (1965) The role of auditory feedback in the control of vocalization in the white-crowned sparrow. $Z$ Tierpsychol 22:770783.

Konishi M (1985) Birdsong: from behavior to neuron. Annu Rev Neurosci 8:125-170.

Korsia S, Bottjer SW (1991) Chronic testosterone treatment impairs vocal learning in male zebra finches during a restricted period of development. J Neurosci 11:2349-2361.

Kubota M, Saito N (1991) NMDA receptors participate differentially in two different synaptic inputs in neurons of the zebra finch robust nucleus of the archistriatum in vitro. Neurosci Lett 125:107-109.

Margoliash D (1983) Acoustic parameters underlying the responses of song-specific neurons in the white-crowned sparrow. J Neurosci 3:1039-1057.

Margoliash D (1986) Preference for autogenous song by auditory neurons in a song system nucleus of the white-crowned sparrow. J Neurosci 6:1643-1661.

Margoliash D (1987) Neural plasticity in birdsong learning. In: Imprinting and cortical plasticity (Rauschecker JP, Marler $\mathbf{P}$, eds), pp 23-54. New York: Wiley.

Margoliash D, Fortune ES (1992) Temporal and harmonic combination-sensitive neurons in the zebra finch's HVC. J Neurosci 12: $4309-4326$.

Margoliash D, Konishi M (1985) Auditory representation of autogenous song in the song system of white-crowned sparrows. Proc Natl Acad Sci USA 82:5997-6000.

Marler P (1970) A comparative approach to vocal learning: song development in white-crowned sparrows. J Comp Physiol Psychol Monogr 71:1-25

Marler $\Gamma$ (1987) Sensitive periods and the roles of specific and general sensory stimulation in birdsong learning. In: Imprinting and cortical plasticity (Rauschecker JP, Marler P, eds), pp 99-135. New York: Wiley.

Marler P, Peters S (1977) Selective vocal learning in a sparrow. Science 198:519-521.

Marler P, Peters S (1982) Subsong and plastic song: their role in the vocal learning process. In: Acoustic communication in birds, Vol II (Kroodsma DE, Miller EH, eds), pp 25-49. New York: Academic.

Marler P, Peters S (1988) The role of song phonology and syntax in vocal learning preferences in the song sparrow, Melospiza melodia. Ethology 77:125-149.

McArthur PD (1986) Similarity of playback songs to self song as a determinant of response strength in song sparrows (Melospiza melodia). Anim Behav 34:199-207.

McGregor PK, Krebs JR (1984) Sound degradation as a distance cue in great tit (Parus major) song. Behav Ecol Sociobiol 16:49-56.

Miyashita $Y$ (1988) Neuronal correlate of visual associative long-term memory in primate temporal cortex. Nature 335:817-820.

Mooney R (1992) Synaptic basis for developmental plasticity in a birdsong nucleus. J Neurosci 12:2464-2477.

Mooney R, Konishi M (1991) Two distinct inputs to an avian song nucleus activate different glutamate receptor subtypes on individual neurons. Proc Natl Acad Sci USA 88:4075-4079.

Morton ES (1982) Grading, discreteness, redundancy and motivational-structural rules. In: Acoustic communication in birds, Vol I (Kroodsma DE, Miller EH, eds), pp 183-212. New York: Academic.

Nordeen EJ, Nordeen KW (1988) Sex and regional differences in the incorporation of neurons born during song learning in zebra finches. J Neurosci 8:2869-2874.

Nordeen KW, Marler P, Nordeen EJ (1989) Addition of song-related neurons in swamp sparrows coincides with memorization, not production, of learned songs. J Neurobiol 20:651-661.

Nottebohm F, Kelley DB, Paton JA (1982) Connections of vocal control nuclei in the canary telencephalon. J Comp Neurol 207:344357.

Okuhata S, Saito N (1987) Synaptic connections of thalamo-cerebral vocal nuclei of the canary. Brain Res Bull 18:35-44.

Perrett DI, Hietanen JK, Oram MW, Benson PJ (1992) Organization and functions of cells responsive to faces in the temporal cortex. Philos Trans R Soc Lond [Biol] 335:23-30.

Petrinovich L, Baptista LF (1987) Song development in the whitecrowned sparrow: modification of learned song. Anim Behav 35:961974.

Richards DG (1981) Estimation of distance of singing conspecifics by the Carolina wren. Auk 98:127-133.

Rodman HR, Skelly JP, Gross CG (1991) Stimulus selectivity and 
state dependence of activity in inferior temporal cortex of infant. monkeys. Proc Natl Acad Sci USA 88:7572-7575.

Rolls ET (1992) Neurophysiological mechanisms underlying face processing within and bcyond the temporal cortical visual areas. Philos Trans R Soc Lond [Biol] 335:11-21.

Rolls ET, Baylis GC, Hasselmo ME, Nalwa V (1989) The effect of learning on the face selective responses of neurons in the cortex in the superior temporal sulcus of the monkey. Exp Brain Res 76:153164

ScharffC, Nottebohm F (1991) A comparative study of the behavioral deficits following lesions of various parts of the zebra finch song system: implications for vocal learning. J Neurosci 11:2896-2913.

Searcy W, Brenowitz EA (1988) Sexual differences in species recognition of avian song. Nature 332:152-154.

Searcy WA, Marler P, Peters SS (1981) Species song discrimination in adult female song and swamp sparrows. Anim Behav 29:997-1003.

Shatz CJ (1990) Impulse activity and the patterning of connections during CNS development. Neuron 5:745-756.
Volman SF, Konishi M (1986) Development of auditory selectivity in a song-system nucleus during song learning. Soc Neurosci Abstr 12:954.

Volman SF, Konishi M (1987) Auditory selectivity in the song-control nucleus HVC appears with the onset of plastic song. Soc Neurosci Abstr 13:870.

Weary DM, Krebs JR (1992) Great tits classify songs by individual voice characteristics. Anim Behav 43:283-287.

Williams H, Nottebohm F (1985) Auditory responses in avian vocal motor neurons: a motor theory for song perception in birds. Science 229:279-282.

Yasukawa K, Bick EI, Wagman DW, Marler P (1982) Playback and speaker-replacement experiments on song-based neighbor, stranger, and self discrimination in male red-winged blackbirds. Behav Ecol Sociobiol 10:211-215.

Young MP, Yamane S (1992) Sparse population coding of faces in the inferotemporal cortex. Science 256:1327-1331. 